\title{
Educação em direitos humanos no currículo das licenciaturas de instituições federais de educação superior
}

\author{
Daiane da Luz Silva ${ }^{1}$ \\ ORCID: 0000-0002-8177-5160 \\ Maria Constantina Caputo ${ }^{1}$ \\ ORCID: 0000-0002-4191-7662 \\ Renata Meira Veras ${ }^{1}$ \\ ORCID: 0000-0002-1681-1401
}

\section{Resumo}

A legislação brasileira contempla a necessidade da inclusão da Educação em direitos humanos na educação básica e superior. Para tanto, faz-se necessário que ela esteja presente na formação de professores, pois estes profissionais são responsáveis por desenvolver e implementar ações e programas de educação formal e não formal em todos os níveis de ensino. 0 objetivo deste estudo é analisar os currículos dos cursos de licenciatura ofertados por instituições federais de ensino superior, para identificar como a Educação em direitos humanos está inserida nesses currículos, tendo por referência a Resolução n. 01/2012 do Conselho Nacional de Educação (CNE). Trata-se de uma pesquisa descritiva-avaliativa, do tipo documental, que incidiu sobre as ementas de 38 currículos de licenciaturas com melhor avaliação no Conceito Preliminar de Cursos 2017, distribuídos em 21 instituições federais de educação e relacionados a 11 áreas: Matemática, Física, Computação e Química, Ciências Biológicas, Educação Física, Filosofıa e Pedagogia, Letras, Artes Visuais e Música. Como resultado, foi possível identificar que as instituições não são omissas, considerando que 36 currículos abordam direitos humanos com conteúdos distribuídos em uma ou mais disciplinas, porém apenas 21\% dos cursos ofertam componente curricular obrigatório específico para o tema, contrariando o que determina o CNE. Conclui-se que é preciso ampliar a inserção da educação em direitos humanos nas licenciaturas e que não se restrinja apenas a uma disciplina ou conteúdos isolados, mas que seja uma formação transversalizada em todo o currículo.

\section{Palavras-chave}

Direitos humanos - Escola justa - Currículos - Licenciaturas - Formação inicial docente - Universidade 


\section{Human rights education in the curricula of undergraduate courses at federal higher education institutions}

\section{Abstract}

The Brazilian law provides for the need of human rights education in both basic and higher education. To this end, it is necessary to include it in basic teacher training, since these professionals are responsible for developing and implementing actions and programs of formal and non-formal education at different levels. In view of this fact, this study aims to analyze the curricula of undergraduate courses offered by federal higher education institutions in order to identify how Human Rights Education plays its role in these curricula according to Resolution n. 01/2012 of the National Board of Education (CNE). This is a descriptive-evaluative documental study which analyzed syllabi of the 38 top-rank undergraduate curricula in 21 federal higher education institutions according to the Preliminary Course Evaluation framework of 2017. It included 11 areas: Mathematics, Physics, Computer Science and Chemistry, Biological Sciences, Physical Education, Philosophy and Pedagogy, Languages, Visual Arts and Music. The analysis conducted showed that the institutions are not neglectful in this regard, considering that 36 curricula examined address Human Rights and can be found in at least one course of each area. However, only $21 \%$ of the curricula of the fields investigated offer a specific mandatory course in the area, contrary to what is determined by the CNE. Thus, conclusion is that Human Rights related themes should not be restricted to a single course or treated in an isolate manner, but included in a wider array of undergraduate courses in order to make curriculum more interdisciplinary and inclusive.

\section{Keywords}

Human rights - Fair school - Curricula - Undergraduate courses - Basic teacher education - University.

\section{Introdução}

A formação de professores em direitos humanos alcançou o status de política pública a partir da publicação das Diretrizes Curriculares Nacionais para a Educação em Direitos Humanos (BRASIL, 2012a). Essa normativa é desdobramento das ações previstas em acordos internacionais pela promoção dos direitos humanos que o Brasil firmou nas últimas décadas (ONU, 1948a, 1948b, 1993, 1994, 1997, 2011; UNESCO, 2006, 2012, 2015). A inclusão nos currículos dos cursos de formação dos profissionais que atuam na educação básica é uma dessas ações a ser implementada pelas instituições formadoras.

Atualmente, a formação de docentes para a educação básica no Brasil é obtida mediante grau acadêmico de licenciatura. As licenciaturas são graduações ofertadas 
por instituições públicas e privadas de ensino superior devidamente credenciadas pelo Ministério da Educação. Os currículos desses cursos são estabelecidos sob autonomia e responsabilidade das instituições, desde que adequados às normas legais vigentes.

0 currículo, compreendido nesse estudo como um artefato socioeducacional ${ }^{2}$ (G00DSON, 2007), é constituído mediante inúmeras implicações sociais, políticas, culturais, éticas, estéticas, que abarcam os instituintes culturais da formação ${ }^{3}$. Implicações essas que nem sempre estão explícitas; nem sempre são coerentes ou absolutas no âmbito das contradições, dilemas e transgressões (MACED0, 2017). Para Sacristán (2013), o currículo não é algo neutro, universal e imóvel, mas território controverso e conflituoso, resultado de tradições, que pode e deve ser revisado e modificado.

É com base nesse posicionamento que se tornar professor é um processo complexo, já que está articulado com a finalidade do currículo oficial, com as legislações educacionais, mas também com as vivências das diversas realidades encontradas no âmbito escolar. Portanto, é preciso pensar o percurso do licenciando como um processo progressivo de aquisição de uma dimensão profissional (NÓVOA, 2019). Nesse sentido, como futuros profissionais da educação é salutar que aprendam conceitos e estratégias pedagógicas para lidar com as questões sociais que impactam o cotidiano dentro e fora da sala de aula, como as advindas das violações aos direitos humanos. É essencial que a educação em direitos humanos esteja presente no processo formativo dos professores, sobretudo porque eles atuarão como multiplicadores desses conhecimentos.

Esse estudo é parte de uma pesquisa de mestrado acadêmico e tem por objetivo analisar os currículos dos cursos de formação de professores mais bem avaliados ofertados por instituições federais de ensino superior para identificar como a educação em direitos humanos está inserida nesses currículos, tendo por referência a Resolução n. 01/2012 do Conselho Nacional de Educação (CNE).

\section{Políticas públicas e suas implicações para a formação de educadores em direitos humanos}

O Brasil é, por definição constitucional, um Estado democrático de direito. É na Constituição Federal que a nação brasileira assume como dever a proteção e garantia de direitos, firmada em uma sociedade justa, fraterna, pluralista, sem preconceitos, pacífica e equânime, sejam eles individuais e/ou sociais, para aguilhoar o bem-estar social (BRASIL, 1988).

Consequentemente, a conscientização acerca desses direitos se faz fundamental para a sua tutela e é por meio da educação que isso se torna possível (NOLETO, 2018). Segundo Boaventura (1996), a educação é um direito público subjetivo, social e universal, além de dever estatal e da família. Para o indivíduo, ela é compulsória; para o Estado, ela envolve encargos e competências materiais e legislativas; para a família, deveres de assistência e de solidariedade; mas, sobretudo, a educação é um direito coletivo porque se conecta com a vida em sociedade, com a participação política, com o desenvolvimento nacional, com

\footnotetext{
2- É uma construção social para fins educacionais específicos, que visa uma formação articulada com processos e procedimentos pedagógicos, na relação com o conhecimento que se elege como educativo (GOODSON, 1997; MACEDO, 2017).

3- "Referências culturais pelas quais o currículo é compreendido, proposto e cotidianamente construído" (MACED0, 2017, p. 84).
} 
a promoção dos direitos humanos e da paz, conecta-se com a pessoa "inserida num dado contexto social e político", não havendo como desvincular o direito à educação do direito à democracia (RANIERI, 2013, p. 78). Relaciona-se, também, com determinantes éticos e ecossustentáveis para a reestruturação de uma sociedade na qual os seres humanos coexistam entre si e com a natureza (GUDYNAS; ACOSTA, 2011).

Por ser um direito de todos, dinamiza e conjuga compromissos em relação à educação em direitos humanos, considerando que os direitos humanos são parte essencial do direito à educação (SILVEIRA et al., 2007).

A escola tem função social nesse processo, pois participa no desenvolvimento das pessoas para pensar, julgar e poder intervir em assuntos coletivos e públicos (PARASKEVA; GANDIN; HYPOLITO, 2004). Os profissionais que nela atuam devem, portanto, estar preparados para lidar e contribuir com as adversidades que atravessam o fazer pedagógico. Assim, é preciso capacitar os professores e professoras para serem agentes socioculturais e políticos, centrados em uma formação cultural e humanista que lhes permita compreender e problematizar a realidade social com vistas à promoção dos direitos humanos (CANDAU et al., 2013). Ao refletir sobre a formação inicial dos professores e indagar quando essa formação realmente começa, Candau et al. (2013) advertem que a formação de professores começa muito antes de ingressarem nos cursos superiores, pois ao chegarem à universidade, os estudantes de licenciatura têm, ao menos, 11 anos de escolarização, nos quais experimentaram vários modelos de formação, geralmente, homogêneos e centrados nos modelos educativos tradicionais. Isso por acreditar que a homogeneidade e a busca pela igualdade, sem considerar as diferenças foi, por muito tempo, critério para a garantia de aprendizagem na estrutura escolar (TRAVERSINI, 2013). Por essa razão, Candau et al. (2013) afirma que, nas políticas de promoção para uma educação em direitos humanos, é basilar a superação da ênfase na igualdade que nega a constituição dos sujeitos e suas diferenças, para uma relação dialética, na qual a igualdade não é oposta à diferença, mas à desigualdade; e lutar por igualdade é lutar para que todos tenham seus direitos reconhecidos, sendo fundamental o reconhecimento da diferença para a construção da igualdade com justiça social.

No contexto brasileiro, as políticas educacionais têm sido implementadas conforme os interesses do Estado (GIROUX, 1997), por consequência, privilegiando as elites, em demérito da população menos favorecida, aprofundando as desigualdades sociais. De acordo com Ball (2002), no que se refere às políticas destinadas à reforma da educação, além de proporcionarem mudanças técnica e estrutural nas organizações, também incidiram em mecanismos para "reformar" professores, ou seja, provocar mudança no que o professor faz, mas também no que o professor é, (re)configurando sua identidade e o que significa ser docente. Macedo (2014, p. 1549) aponta que "está em curso a construção de uma nova arquitetura de regulação", na qual "os sentidos hegemonizados para educação de qualidade estão relacionados à possibilidade de controle do que será ensinado e aprendido" (MACEDO, 2014, p. 1549). Entre essas alternativas de controle está o discurso performativo que tenta amplamente desqualificar a universidade e a formação inicial de professores, taxando-os de mal preparados e mal formados (MACED0, 2014).

Por outro lado, Apple (2017) sinaliza que políticas e práticas democráticas densas ainda sobrevivem em muitos espaços por causa do trabalho duro, contínuo, dos sacrifícios de professores, dos membros da comunidade e dos movimentos sociais. Os avanços 
significativos, no que se refere à educação brasileira, foram alcançados mediante os esforços desses profissionais e dos representantes dos movimentos em prol das classes populares. Logo, para pensar a formação de professor é necessário considerar as forças políticas que atuam no cenário educacional nacional, impregnadas pela geopolítica global neoliberalista, mas também resultantes de lutas contra-hegemônicas travadas por aqueles que não aceitam as injustiças advindas dessas forças de opressão (SANTOS, 2011).

Foram os debates acerca das demandas sociais que têm como preocupação a formação de professores, atrelados às demandas políticas internacionais, que suscitaram a criação de algumas medidas governamentais no Brasil (SILVA; TAVARES, 2013). Todavia, somente a partir de 2001, o CNE passou a elaborar as diretrizes curriculares nacionais para regulamentar os cursos de graduação para formação de professores (BRASIL, 2020). Entre essas diretrizes, cabe destacar as que deram maior ênfase aos conhecimentos pertinentes aos direitos humanos como parte da formação dos licenciandos: a Resolução n. 01/2012 do CNE que instituiu as Diretrizes Curriculares Nacionais para a Educação em Direitos Humanos; as resoluções do CNE n. 01/2015 e n. 02/2015 que instituíram as Diretrizes Curriculares Nacionais para a formação de profissionais do magistério para a educação básica e, respectivamente, a formação de professores indígenas. As duas últimas são reflexos das propostas previstas no Plano Nacional de Educação, Lei n 13.005/2014 (DOURAD0, 2015; BRASIL, 2014), marcos de uma etapa mais progressista das políticas de fomento à qualificação para o magistério. Todas elas expressam a obrigatoriedade da educação em direitos humanos para a formação de profissionais da educação.

No entanto, nos últimos anos sobrevieram expressivas mudanças de cunho político que impactaram o sistema educacional brasileiro e, especificamente, nas ações direcionadas à formação inicial de professores: "[...] se desenhou uma nova configuração de poder no âmbito do Ministério da Educação (MEC) com a consequente alteração na correlação de forças do CNE mediante a revogação da portaria de recondução e nomeação dos novos conselheiros" (AGUIAR, 2018, p. 8).

A partir de então, algumas medidas políticas foram tomadas à revelia de vários representantes da sociedade civil e instituições educacionais, entre elas, a revogação da Resolução n. 02/2015 do CNE, e, como substituta, a aprovação da Base Comum Nacional (BNC) para a formação docente (ANPED, 2019). Essa base, em comparação com as diretrizes revogadas, trouxeram alguns recuos para a formação, como a ênfase na disciplinaridade e na formação por competências. Apesar de citar direitos humanos como conteúdo, não explicita a concepção e nem fundamenta o que se compreende por direitos humanos, tampouco indica suas implicações no processo formativo para o magistério, além de ser omissa sobre os temas que transversalizam os direitos humanos, tais como a compreensão e o respeito à diversidade de gênero, sexual, religiosa, de faixa geracional, bem como o aprendizado da Língua Brasileira de Sinais (Libras).

Diante de tais ações governamentais, pode-se observar que hoje ainda prevalece o desprestígio da profissão docente, alinhado a uma formação estadocêntrica, ou seja, centrada nos interesses do Estado (LOPES; MACEDO, 2011), que privilegia a manutenção da opressão e a negação de qualidade formativa para o sistema educacional, dado seu descaso histórico pela educação pública e o desrespeito aos debates e contribuições dos representantes dos mais diversos setores sociais que se mobilizam para lutar por qualidade na educação (ANPED, 2019). 


\section{Metodologia}

Este é um estudo exploratório e descritivo-avaliativo, de abordagem qualitativa, do tipo documental. 0 recorte metodológico incidiu sobre as licenciaturas ofertadas por Instituições Federais de Educação Superior (IFES) com melhor avaliação no Conceito Preliminar de Cursos (CPC) 2017, ou seja, conceito 5. Os dados do CPC foram obtidos por meio do acesso ao site institucional do MEC, que os mantém para consulta pública e sistematizados em planilha de dados. Os documentos curriculares foram os disponibilizados pelas IFES em seus sites institucionais. A opção pelo CPC justifica-se por ser um recurso utilizado pelo MEC como indicador de qualidade dos cursos de graduação. 0 conceito é obtido com base no resultado dos estudantes no Exame Nacional de Desempenho dos Estudantes (ENADE), no valor agregado pelo processo formativo oferecido pelo curso, na formação e regime de trabalho do corpo docente e na percepção discente sobre as condições do processo formativo (BRASIL, 2018).

\section{Universo da pesquisa}

As 39 licenciaturas que obtiveram conceito 5 no CPC 2017 estão distribuídas em 21 IFES, sendo 19 universidades e 2 institutos. A representação quantitativa por campo do conhecimento está disposta na figura 1:

Figura 1 - Quantitativo de licenciaturas analisadas por campo do conhecimento

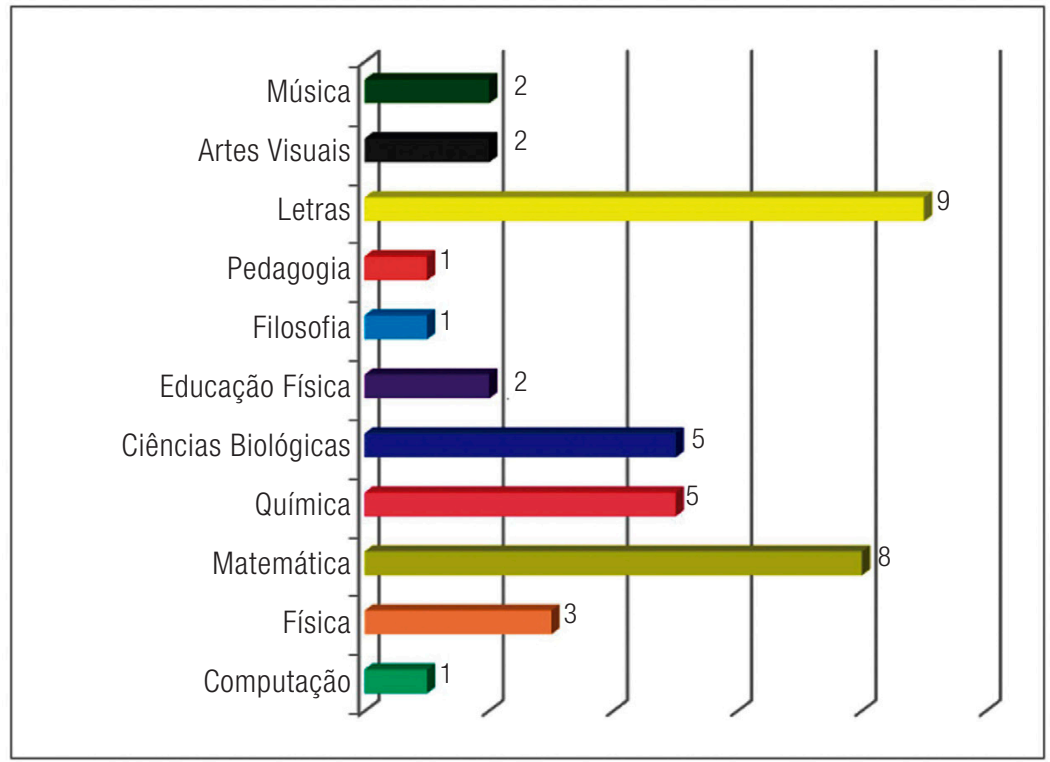

Fonte: Elaborado pelas autoras (2020).

Desses cursos, 17 estão relacionados às ciências exatas (Matemática, Física, Computação e Química), 05 às ciências biológicas, 04 relacionados às ciências humanas 
(Educação Física, Filosofia e Pedagogia), 9 às letras (Português, Italiano, Espanhol e Inglês) e 4 relacionados às artes (Artes Visuais e Música).

\section{Procedimentos}

A fonte dos dados da pesquisa são os documentos oficiais de acesso público, disponibilizados pelas IFES: projetos pedagógicos e/ou as respectivas ementas dos currículos das licenciaturas. Quanto ao procedimento da análise documental, para a codificação de dados e estabelecimentos de categorias foram necessárias algumas operações sistemáticas (RICHARDSON, 2012), mediante as seguintes etapas: (1) análise preliminar e classificação dos documentos; (2) a exploração do material e a sistematização dos dados e organização em categorias predefinidas; (3) tratamento dos resultados das etapas antecedentes, mediante interpretações indutivas e dedutivas (CELLARD, 2008). A categoria e as subcategorias preestabelecidas, a partir do referencial normativo e norteador da pesquisa, foram:

a. categoria principal: currículos das licenciaturas ofertadas por IFES com conceito 5 no CPC 2017;

a.1 subcategorias: formas de inserção da educação em direitos humanos:

a.1.1 componentes curriculares obrigatórios específicos sobre a temática;

a.1.2 conteúdos inseridos em componentes curriculares obrigatórios;

a.1.3 outras formas.

Após acesso aos projetos pedagógicos dos cursos e/ou às suas respectivas ementas, ressalta-se que, dos 39 currículos, foi possível ter acesso às ementas de 38 currículos, 32 cursos têm o projeto pedagógico para consulta e 6 disponibilizaram apenas as ementas. Apenas educação física da Universidade Federal do Ceará não disponibilizou no site as informações necessárias à pesquisa. Para auxiliar na análise do conteúdo das ementas foi utilizado como instrumento acessório o software livre Iramuteq. Amplamente utilizado em pesquisas qualitativas, ele possibilita, por meio do processamento de dados, análises estatísticas de textos (CAMARG0; JUSTO, 2013a).

Além desse recurso as ementas também foram submetidas a uma análise criteriosa, na qual foram identificados dados objetivos e subjetivos, que não foram possíveis de serem obtidos com o software.

Dentre essas formas de análise, considerou-se mais adequada para esse tipo de estudo a nuvem de palavras, que possibilitou rápida identificação das palavras-chave em maior frequência no contexto textual (CAMARG0; JUSTO, 2013b; KAMI, 2016).

Para identificação dos conteúdos pertinentes aos temas, seguiu-se a categorização clássica dos direitos humanos adotada por vários autores, incluindo as concepções apresentadas por Ramos (2017) e Oliveira e Lazari (2018), partindo das primeiras classificações do jurista Karel Vasak e as atualizações em dimensões de Paulo Bonavides (RAMOS, 2017). Com base nesses autores e nas normas legais discutidas nesse estudo, buscou-se sistematizar os temas no quadro a seguir: 
Quadro 1 - Dimensões dos direitos humanos e temas relacionados

\begin{tabular}{ccc}
\hline Dimensões & Temas relacionados aos Direitos Humanos \\
\hline $1^{\mathrm{a}}$ & direitos de liberdade, individuais, civis e políticos: direito à vida, liberdade, personalidade, acesso à justiça, direitos \\
& humanos penais, nacionalidade, direitos políticos.
\end{tabular}

Fonte: Elaborado pelas autoras (2020) com base nos estudos de Ramos (2017) e Oliveira e Lazari (2018).

A partir do quadro acima foi possível relacionar os temas de direitos humanos com os conteúdos encontrados nos currículos, resultando em dados relevantes para atingir o objetivo norteador da pesquisa.

\section{Discussão e resultados}

Discorrer acerca do currículo implica reflexões sobre diversos elementos centrais da educação, entre eles, a qualidade, a inclusão e a relevância de determinados conteúdos e suas abordagens, pois os estudos sobre currículo levam a entender quais são os objetivos, o imaginário social e as aspirações que se buscam alcançar em um sistema de educação eficaz (OPERTTI; KANG; MAGNI, 2018). Da mesma maneira, tais estudos evidenciam que o currículo é constituído mediante escolhas dos conhecimentos que os atores educativos consideram necessários em detrimento da omissão daqueles que elegem como irrelevantes (SILVA, 2017), além de revelar que as normativas educacionais impactam diretamente na construção dos currículos, uma vez que trazem imposições estatais para esse campo (LOPES, 2006).

Portanto, acredita-se que as instituições investigadas, ao elegeram educação de direitos humanos como conteúdo relevante para os cursos de formação inicial para a docência, estão se posicionando politicamente. Compreende-se que tal direcionamento curricular possa contribuir com a formação de cidadãos ativos, socialmente comprometidos e, por consequência, capazes de promover debates contínuos em torno do tema no cotidiano laboral e social. Nesse sentido, considera-se necessário apresentar inicialmente o mapeamento dos cursos mais bem avaliados e, posteriormente, como inserem a temática direitos humanos em seus currículos.

\section{Mapeamento dos cursos que obtiveram melhor avaliação no CPC 2017}

Os resultados apontaram que no CPC 2017, realizado pelo Instituto Nacional de Estudos e Pesquisas Educacionais Anísio Teixeira (INEP) do MEC, foram avaliadas 5.088 licenciaturas. Destas, 4.652 licenciaturas estão na modalidade presencial, o que corresponde a cerca de 91\% dos cursos avaliados. Dentre as presenciais, 2.317 (45,54\%) são ofertadas por Instituições de Educação Superior Públicas, sendo 1.298 pertencentes à categoria administrativa federal. Destaca-se que, das federais, 39 instituições obtiveram o conceito máximo, conforme representado no quadro abaixo: 
Educação em direitos humanos no currículo das licenciaturas de instituições federais de educação superior

Quadro 2 - Licenciaturas por IFES com conceito 5 no CPC 2017

\begin{tabular}{|c|c|c|c|c|}
\hline Área & Currículo & IFES & Sigla da IFES & Município \\
\hline \multirow{17}{*}{ I } & Computação & UF do Paraná & UFPR & Palotina \\
\hline & \multirow{3}{*}{ Física } & UF de Viçosa & UFV & Florestal \\
\hline & & UF de Juiz de Fora & UFJF & Juiz de Fora \\
\hline & & UF de Santa Maria & UFSM & Santa Maria \\
\hline & \multirow{8}{*}{ Matemática } & UF de Ouro Preto & UFOP & Ouro Preto \\
\hline & & UF de Viçosa & UFV & Florestal \\
\hline & & UF de Santa Maria & UFSM & Santa Maria \\
\hline & & UF de Santa Catarina & UFSC & Blumenau \\
\hline & & UF de Alfenas & UNIFAL-MG & Alfenas \\
\hline & & IFECT do Rio Grande do Sul & IFRS & Canoas \\
\hline & & FUF do Abc & UFABC & Santo André \\
\hline & & UF da Fronteira Sul & UFFS & Chapecó \\
\hline & \multirow{5}{*}{ Química } & UF de Juiz de Fora & UFJF & Juiz de Fora \\
\hline & & UF do Rio Grande do Sul & UFRGS & Porto Alegre \\
\hline & & UF de Santa Catarina & UFSC & Blumenau \\
\hline & & IF de São Paulo & IFSP & Sertãozinho \\
\hline & & FUF do Abc & UFABC & Santo André \\
\hline \multirow{5}{*}{$\|$} & \multirow{5}{*}{ Ciências Biológicas } & UF do Paraná & UFPR & Palotina \\
\hline & & UF de Goiás & UFG & Jataí \\
\hline & & UTF do Paraná & UTFPR & Santa Helena \\
\hline & & IFECT de São Paulo & IFSP & Avaré \\
\hline & & FUF do Abc & UFABC & Santo André \\
\hline \multirow{4}{*}{ III } & \multirow{2}{*}{ Educação Física } & UF do Ceará & UFC & Fortaleza \\
\hline & & UF de Lavras & UFLA & Lavras \\
\hline & Filosofia & UF de Santa Maria & UFSM & Santa Maria \\
\hline & Pedagogia & UII da Lusofonia Afro-Brasileira & UNILAB & Redenção \\
\hline \multirow{9}{*}{ IV } & Letras-Português & UF do Paraná & UFPR & Curitiba \\
\hline & Letras-Português Italiano & UF do Paraná & UFPR & Curitiba \\
\hline & \multirow{3}{*}{ Letras-Português e Inglês } & UF do Paraná & UFPR & Curitiba \\
\hline & & UF do Ceará & UFC & Fortaleza \\
\hline & & FUF do Pampa & UNIPAMPA & Bagé \\
\hline & \multirow{2}{*}{ Letras-Português e Espanhol } & UF dos Vales do Jequitinhonha e Mucuri & UFVJM & Diamantina \\
\hline & & UF da Fronteira Sul & UFFS & Realeza \\
\hline & \multirow{2}{*}{ Letras - Inglês } & UF do Paraná & UFPR & Curitiba \\
\hline & & UF de Santa Catarina & UFSC & Florianópolis \\
\hline \multirow{4}{*}{ V } & \multirow{2}{*}{ Artes Visuais } & Universidade de Brasília & UNB & Brasília \\
\hline & & UF de Juiz de Fora & UFJF & Juiz de Fora \\
\hline & \multirow{2}{*}{ Música } & UF de Uberlândia & UFU & Uberlândia \\
\hline & & UF de Santa Maria & UFSM & Santa Maria \\
\hline
\end{tabular}

Legenda:

IFECT = Instituto Federal de Educação, Ciência e Tecnologia

FUF = Fundação Universidade Federal

UTF = Universidade Tecnológica Federal

UII = Universidade da Integração Internacional

UF $=$ Universidade Federal

Fonte: Elaborado pelas autoras (2020). 
De acordo com Bittencourt et al. (2010), as avaliações do CPC demonstram a predominância de melhor conceito nos cursos ofertados por universidades públicas em comparação com as instituições privadas, sendo um fator relevante nas públicas a ampla superioridade de professores com doutorado, em regime de tempo parcial ou integral e, também, melhor desempenho dos estudantes no ENADE.

As IFES com maior número de licenciaturas avaliadas com conceito máximo são ofertadas pelas Universidades Federais: do Paraná (6), de Santa Maria (4), de Santa Catarina (3), de Juiz de Fora (3) e do ABC (3). A figura 2 mostra o quantitativo de cursos por IFES:

Figura 2 - Licenciaturas com CPC 5 por IFES

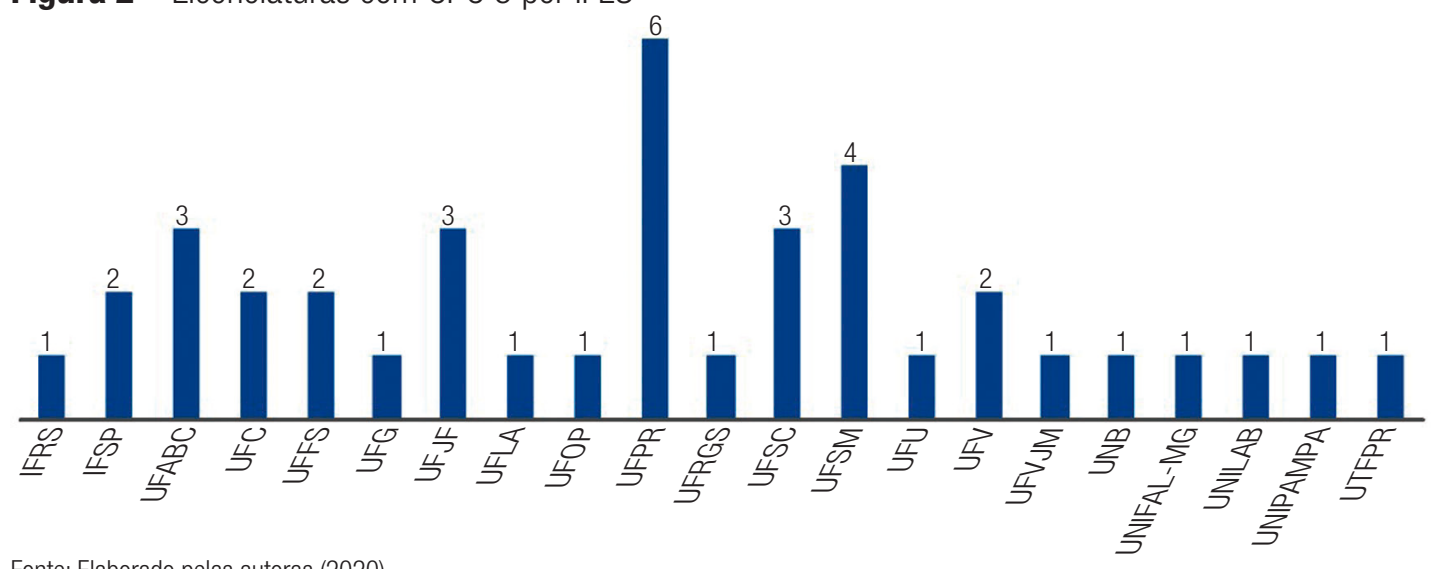

Fonte: Elaborado pelas autoras (2020).

Notou-se, além disso, que há predominância de cursos da Área I (Ciências Exatas), seguida da Área IV (Letras e suas habilitações). Contudo, para identificar as razões pelas quais se justifica esse resultado, é preciso considerar inúmeros fatores, entre eles, o contexto de inserção dos cursos, observando os indicadores socioeconômicos e regionais, gestão acadêmica do curso e de gestão institucional, alinhada à cultura de avaliação, categoria administrativa, organização acadêmica (BRASIL, 2015), entre outros fatores, que ensejariam um outro estudo.

\section{Formas de inserção da educação em direitos nas licenciaturas melhor avaliadas no CPC/2017}

Há dois critérios normativos importantes a serem considerados na análise dos currículos das licenciaturas. 0 primeiro, referente à Resolução n. 01/2012 do CNE, quanto às possibilidades de inserção dos conhecimentos concernentes à educação em direitos humanos na organização dos currículos da educação básica e da educação superior, que podem ser: pela transversalidade e tratados interdisciplinarmente; como um conteúdo específico de uma das disciplinas já existentes; combinando transversalidade e disciplinaridade; outras formas de inserção (BRASIL, 2012b, p. 2, art. $7^{\circ}$, I, II, III). Quanto à formação inicial e continuada dos profissionais da educação, a educação em direitos humanos deverá ser componente curricular obrigatório (BRASIL, 2012b, p. 2, art. 8).

Em relação ao segundo critério, há que se considerar o que preconizam os instrumentos de avaliação da qualidade dos cursos de graduação geridos pelo INEP, especificamente, o indicador 
1.5, na dimensão da organização didático-pedagógica, que traz como indicador a abordagem de conteúdos pertinentes às políticas de educação em direitos humanos (BRASIL, 2017).

Uma das consequências dessa avaliação é que os cursos poderão receber conceito mais baixo em caso de não observância aos indicadores de qualidade. Esse conceito, além de subsidiar as decisões regulatórias do MEC, tem impacto sobre os atos de autorização, reconhecimento e renovação de reconhecimento dos cursos de graduação (BRASIL, 2017). Desse modo, ao analisar os currículos, foi possível identificar duas formas de inserção: disciplinar e multidisciplinar. Esta última tem predominância em relação à primeira, ou seja, conteúdos de direitos humanos distribuídos em disciplinas já existentes no currículo, opção adotada na maioria dos currículos analisados.

A organização disciplinar, tal qual se apresenta nos dias atuais, se configurou no decorrer do século XIX com o surgimento das universidades modernas, ganhando novos contornos a partir do século XX com o impulsionamento gerado à pesquisa científica (MORIN, 2003). Para Morin (2003), isso significa que a história da disciplinaridade tem suas raízes na universidade, que, por consequência, se inscreve na história da sociedade, ao instituir a divisão e a especialização do trabalho. Esse modelo curricular, ao longo do tempo, tem se caracterizado pela sua fragmentação e hierarquização de saberes (GALLO, 2000). No que se refere à organização multidisciplinar, ela se constitui como uma associação de disciplinas que tratam de temas comuns, articulando, algumas vezes, bibliografia, técnicas de ensino e procedimentos de avaliação, mas sem evidenciar uma devida inter-relação e conexão entre elas, ao menos no currículo oficial (ALMEIDA FILHO, 1997).

De acordo com Candau et al. (2013), a configuração curricular na educação euperior deve dar enfoque aos direitos humanos mediante proposta de viés educativo e plural, presente em todo o currículo, e essa transversalização deve se concretizar a partir de práticas pedagógicas concomitantemente interculturais, interdiscursivas e interdisciplinares.

Para Braga, Machado e Guimarães-Iosif(2014), o Brasil ainda mantém uma tradição de não privilegiar a formação interdisciplinar, que, segundo eles, é salutar para agregar conhecimentos que vão além dos conteúdos tradicionais, devendo partir do princípio da educação cidadã, com viés humano, social e político. Entretanto, o modelo curricular interdisciplinar, nada mais é do que um modelo disciplinar, uma vez que não se faz interdisciplinaridade sem disciplinas, sendo sua superação a proposta curricular transdisciplinar (GALLO, 2000).

Desse modo, Santos (2008) diz que a transdisciplinaridade propõe outra forma de pensar os problemas contemporâneos ao se contrapor aos princípios cartesianos de fragmentação do conhecimento e dicotomia das dualidades. A proposta de transversalidade nos currículos universitários e escolares implicaria novos formatos diferenciados do que se concebe hoje como espaço formal de aprendizagem, e, sobretudo, abrigaria, de forma muito mais ampliada e sem o engessamento dos formatos anteriores, os conteúdos para uma educação em direitos humanos.

No entanto, Candau et al. (2013) sinalizam que elaborar um projeto pedagógico de curso que se constitua em uma proposta de formação de docentes em direitos humanos que seja transversal, interdisciplinar ou transdisciplinar, é um trabalho complexo; por isso, na maioria das vezes, fica condicionado à justaposição de disciplinas desarticuladas. Uma possibilidade para ter, ao menos, no currículo, uma abordagem coesa sobre o tema, é reunir em um componente curricular os principais conteúdos que versam sobre educação 
em direitos humanos, conforme previsto pela Resolução n. 01/2012 do CNE, para início propositivo de uma ação formacional, que, posteriormente, pode ir se desencadeando em uma inserção integral do tema.

Com base nesses referenciais, constatou-se que, dos 38 currículos, somente $21 \%$ estão em conformidade com o artigo $8^{\circ}$ da Resolução $n$. 01/2012 do CNE. São eles: Química do IFSP e da UFSC; Música da UFU; Matemática da UFSM, UNIFAL-MG, UFFS, UFSC e do IFRGS. Apesar disso, foi possível identificar que 36 dos 38 currículos têm conteúdos de direitos humanos inseridos em componentes curriculares obrigatórios que abordam outros temas.

Outras formas de inserção também foram observadas a partir da leitura dos projetos pedagógicos disponíveis e das matrizes curriculares, com suas respectivas ementas. Porém, os achados não se referem ao caráter obrigatório, mas de opção dos estudantes, como disciplinas optativas, atividades complementares, ações extensionistas e de pesquisa, que por ser de livre escolha dos licenciandos, não permite identificar se eles passarão ou não por essa formação. Mesmo assim, compreende-se a importância da educação em direitos humanos ser incluída em alternativas curriculares, pois, possivelmente, irá ampliar as opções sobre o tema e agregar conhecimentos e experiências formativas para os discentes.

No que se refere à transversalização, identificou-se que os currículos dos cursos seguem a estrutura disciplinar e sequencial, sem evidenciar metodologias que denotassem as formas interdisciplinares, ou seja, possibilidades de estabelecer conexões entre os conceitos e as interpretações próprias de cada disciplina (JORDELET, 2016), no tocante à inserção dos temas relacionados aos direitos humanos e/ou conteúdos de direitos humanos que abarcassem todo o currículo.

Segundo Gatti (2010), essa concepção curricular tem raízes históricas, pois o currículo dos cursos de formação docente se caracteriza por ser fragmentário e, mesmo com ajustes parciais em razão das novas diretrizes, verifica-se a predominância do caráter disciplinar dessas licenciaturas.

Para identificar nos currículos a inserção disciplinar em componentes curriculares específicos e os contidos nas já existentes no currículo, o uso do Iramuteq possibilitou a visualização e disposição dos termos mais frequentes no texto. A nuvem de palavras abaixo ilustra o conjunto dos termos com maior evidência no conjunto de todos os currículos analisados.

Figura 3 - Nuvem de palavras: temas de direitos humanos mais recorrentes

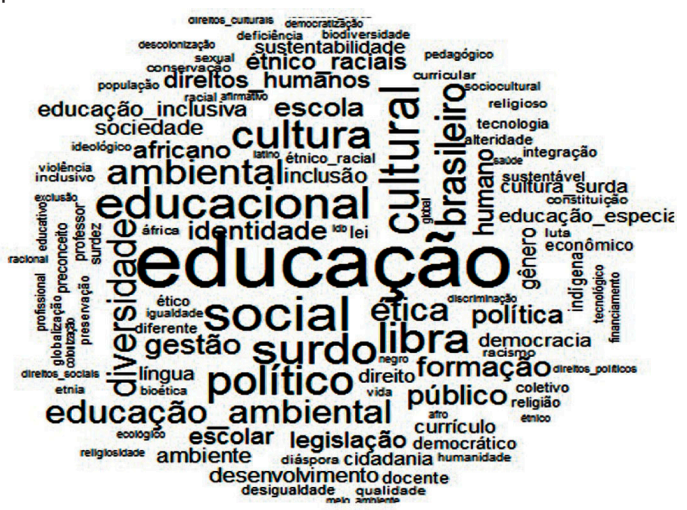

Fonte: Elaborado pelas autoras (2020) 
Observou-se que o eixo central é o termo "educação", ou seja, o termo que aparece com maior frequência nos currículos. Outros temas mais evidentes são: Libras/surdos, educação ambiental, diversidade, cultura, ética, direitos humanos, política, étnico-racial e outras com menor incidência: inclusão, gênero, democratização, descolonização, igualdade entre outros.

A proximidade do termo educação relacionado aos conteúdos de direitos humanos, por meio da abordagem diversificada de temas nos currículos, leva a crer na intencionalidade em constituir currículos que objetivam a formação de docentes mais engajados com a formação humanística e politizados. Segundo Gadotti (2003), o estudante politizado é um estudante que tem motivação pela qualidade do que é ensinado, passa a exigir explicações, motiva o professor, tem interesse pelas relações humanas estabelecidas no ambiente formativo. Por consequência, serão professores mais conscientes de que toda prática educativa é uma atuação política (FREIRE, 2003) e que educar em direitos humanos é inerente a esta prática.

Dos temas encontrados com maior ocorrência e de relevância para esse estudo, destaca-se:

Quadro 3 - Temas mais recorrentes

\begin{tabular}{c|c}
\hline Temas & Temas relacionados ao mais frequente \\
\hline Educação & $\begin{array}{r}\text { educação ambiental, gestão democrática, globalização pluralidade de gênero, sexual, } \\
\text { étnico-racial e geracional e formação com ênfase em conteúdos que abordam } \\
\text { discriminação e preconceito }\end{array}$ \\
\hline Libras & \begin{tabular}{r} 
educação inclusiva, educação especial, identidade surda, cultura surda, cidadania \\
\hline Cultura/ Diversidade Cultural \\
ética, bioética, africano, indígena, religião, diversidade religiosa e étnica, \\
desenvolvimento sustentável, alteridade, descolonização e outros
\end{tabular} \\
\hline direitos sociais, políticos e democratização
\end{tabular}

Fonte: Elaborado pelas autoras (2020).

Essa última análise possibilitou visualizar um detalhamento maior dos temas com maior frequência. Identificou-se, também, que são temas alinhados aos discursos póscríticos sobre o currículo, ou seja, que põem em contraste e questionam os arranjos sociais e educacionais emergentes, desafiam o status quo, trazendo para a construção curricular temas que discutem as desigualdades e injustiças sociais como alteridade, diferença, descolonização e pluralidade (SILVA, 2017). São conteúdos atuais e pautas reivindicadas pelos movimentos dos grupos sociais sub-representados, em busca de reconhecimento e garantias de seus direitos, que não devem passar ocultados ou neutros na formação docente, pois, de acordo com Gadotti (2003), o educador nessa sociedade não pode ser neutro: ou educa em favor dos desfavorecidos ou contra eles. Porque, para esse autor, a escola, campo de atuação do professor, não está neutra e nem isenta das influências e tensionamentos gerados pelos acontecimentos sociais, políticos, culturais, econômicos e ideológicos.

Nessa perspectiva, compreende-se que seja qual for o campo do conhecimento em que a licenciatura esteja centrada, é indispensável que temas inerentes à educação em direitos humanos integralizem a formação para o magistério em todas as áreas (SILVA, et al., 2013). 
$\mathrm{Na}$ análise conjunta dos currículos por campo do conhecimento, buscou-se identificar também as ênfases, ou seja, conteúdos com maior frequência no corpus textual, e constatou-se que os currículos com mais conteúdos são os de: artes visuais, ciências biológicas, filosofia pedagogia, matemática, música, letras e física; e com menor ênfase são os de: computação, educação física e física. Exclui-se dessa análise os cursos de física da UFSM e matemática da UFOP que não abordam conteúdos de direitos humanos em seus currículos. Ressalta-se que o primeiro currículo está datado em 2005. Se não foi atualizado desde essa data, a obsolescência explica o não atendimento às Diretrizes para a Educação em Direitos Humanos, que foi publicada em 2012. Quanto ao segundo currículo, não foi possível ter acesso a todas as ementas dos componentes curriculares obrigatórios, fator que prejudicou a análise, pois a IFES publicou parcialmente os conteúdos desses componentes. Por outro lado, a UNB também mantém disponível as ementas de poucos componentes curriculares obrigatórios do curso de artes visuais, e, mesmo nos poucos disponíveis, foi possível identificar a presença de conteúdos de direitos humanos.

Portanto, incluir a educação em direitos humanos é uma exigência normativa, mas também é uma opção, considerando a autonomia das IFES de atender ou não os ditames normativos, mesmo incorrendo na possibilidade de obter sanções por parte dos órgãos governamentais de avaliação e regulação da educação superior. Essa foi a opção dos atores envolvidos na elaboração do currículo do curso de ciências biológicas do IFSP. No projeto pedagógico desse curso está presente o reconhecimento do que determina a Resolução n. 01/2012 do CNE, porém optaram por instituir um componente curricular dedicado à temática direitos humanos e, em vez de mantê-lo como obrigatório, de acordo com o art. $8^{\circ}$ desta norma, decidiram incluí-lo no rol de componentes curriculares optativos.

Infere-se que os destaques ao tema dados em cada currículo refletem "o quê" os atores pedagógicos envolvidos com a seleção dos conhecimentos, consideram relevante para a formação dos licenciandos. Essas opções curriculares revelam que, "o currículo está implicado em relações de poder", "transmite visões sociais particulares" e "produz identidades sociais individuais particulares” (MOREIRA; SILVA, 2002, p. 8). Tanto pode ser um instrumento de alienação e negação de determinados saberes, como pode ser politicamente engajado com as demandas sociais, sobretudo, sendo um meio salutar para a emancipação crítica e intelectual dos aprendizes, bem como para a transformação das relações de poder (MOREIRA; SILVA, 2002).

Para Arroyo (2003), ao pensar o currículo, deve-se considerar a diversidade dos sujeitos sociais e de protagonistas que fazem parte desse constructo. De acordo com esse autor, cada área do currículo lê o conhecimento do seu ângulo e tende, muitas vezes, a deixar de fora saberes construídos e acumulados pela pluralidade e diversidade de protagonistas sociais, que não são reconhecidos por serem tidos como marginais às lógicas de saberes tradicionalmente considerados importantes para o saber científico e intervir político, como "o direito de ter direitos" (ARENDT, 1989, p. 332) e de reconhecimento dos saberes autóctones e de etnias marginalizadas como as indígenas, africanas, ciganas, entre outras. Santomé (2013) afirma que os currículos explícitos e enfatizados, na maioria das propostas curriculares das instituições, chamam a atenção para a presença maciça das culturas hegemônicas e o silenciamento das culturas e vozes dos grupos sociais que 
não dispõem de estruturas importantes de poder; e quando aparecem, geralmente, são deturpadas ou eivadas de preconceitos e discriminações.

Nos currículos estudados, a maioria dos conteúdos encontrados aborda temas de direitos humanos relacionados aos grupos minoritários, por meio dos conteúdos que tratam sobre relações étnico-raciais e correlatos (preconceito, discriminação, colonização, descolonização, diásporas culturas e identidades africanas e indígenas), e demais diversidades (sexual, geracional, de gênero). Temas relevantes nos debates sobre a temática, considerando que são esses grupos os que mais sofrem com violações de direitos.

Para Santos e Martins (2019), a concepção hegemônica global sobre direitos humanos como linguagem de dignidade humana e direito universal convive com a constatação de que a maioria da população mundial não é sujeito de direitos, mas objeto de seus discursos, principalmente, aqueles que sofrem sistêmicas opressões impostas pelo capitalismo, colonialismo e patriarcado.

De acordo com Candau (2002), a história brasileira está marcada pela eliminação do "outro" e da negação violenta da alteridade, por isso, se faz necessário, para democratização da sociedade e das práticas educativas e curriculares, a promoção de direitos básicos de todos. Todavia, sem limitar os direitos das pessoas, mas pensando em uma sociedade que atua em harmonia com o meio ambiente e com todos os seres que nele habitam. É uma compreensão de direitos humanos que se afasta dos ideais colonialistas, não marginaliza os povos não europeus, como os afro-ameríndios no Brasil, e que também está alinhada ao conceito de direitos humanos do bem viver (GARCIA, 2015). 0 bem viver é uma ética, advinda das epistemologias latino-americanas, que deve nortear as ações estatais de promoção aos direitos humanos para, enfim, poder "construir outra sociedade sustentada na comunidade, na convivência do ser humano em diversidade e em harmonia com a natureza, a partir do reconhecimento dos diversos valores culturais existentes em cada sociedade em particular em todo o planeta”. (GARCIA, 2015. p. 254). Nos currículos estudados, infere-se que há alusão a essa problematização nos conteúdos: educação ambiental e desenvolvimento sustentável (quadros 4 e 5), meio ambiente, biodiversidade, preservação, ecológico (figura 3). Nesse viés, as instituições educacionais têm importante missão quando se posicionam com propostas e ações contra-hegemônicas e de articulação da negação da padronização do caráter monocultural presentes nos currículos e lutam contra todas as formas de desigualdade presentes na nossa sociedade e na educação.

Fazer educação nos parâmetros de uma cultura de direitos humanos é demanda tanto da comunidade internacional, quanto da comunidade nacional, com apelo ao fortalecimento da democracia nas sociedades. Porém, compreende-se que é um grande desafio para todas as áreas do conhecimento da educação superior (SILVA; TAVARES, 2013), principalmente, considerando as políticas públicas que, muitas vezes, atuam contra o pleno desenvolvimento social e educacional (APPLE, 2005). No entanto, as instituições educativas podem e devem deixar de ser o lugar "em que se aprende apenas o básico e se reproduz o conhecimento dominante, para assumir que precisam ser uma manifestação de vida em toda a sua complexidade", como ensinar "a complexidade de ser cidadão e as diversas instâncias em que se materializa: democrática, social, solidária, igualitária, intercultural e ambiental” (IMBERNÓN, 2011, p. 8). Nesse ínterim, a formação 
do educador em direitos humanos é, na atualidade, um caminho a mais para a construção de uma educação que promova o empoderamento e fomente as capacidades dos atores curriculares na constituição de currículos centrados nessa temática, tendo a consciência de que "a formação é o estágio inicial, mas que o processo educativo em direitos humanos é contínuo" (TAVARES, 2007, p. 487).

\section{Considerações finais}

A elaboração dos projetos pedagógicos de cursos para formar profissionais da educação deve estar relacionada à formação para uma ativa atuação em sociedade com responsabilidade social, ética e humana.

Entende-se que os currículos são estruturados mediante uma seleção de conhecimentos considerados relevantes por seus atores curriculares, a partir das múltiplas cosmovisões e implicações culturais e experienciais deles, mas que também são frutos de arcabouços normativos, muitas vezes impostos pelo poder executivo gestor de forma arbitrária e sem respeitar o pleno debate democrático e a autonomia universitária.

Das omissões e opções curriculares na formação de professores, sejam as advindas do legislador e/ou das instituições formadoras, compreende-se que elas evidenciam que tipo de currículo se objetiva ter, qual perfil profissional pretende-se formar. Desse modo, constatou-se que as licenciaturas com maior conceito no CPC são ofertadas por instituições públicas federais e que a grande maioria são universidades.

Nos currículos analisados, foi possível identificar duas formas de inserção: disciplinar, na qual há a existência de um componente curricular obrigatório específico para o tema; e multidisciplinar, na qual os diversos conteúdos correlatos ao tema estão inseridos em disciplinas que abordam outros temas. Dos 38 currículos, apenas 8 atendem ao artigo $8^{\circ}$ da Resolução n. 01/2012 do CNE, ou seja, têm componente curricular obrigatório. Todavia, a forma multidisciplinar é predominante na constituição de 36 dos 38 currículos analisados. Também foi identificado que 16 desses currículos estão com data de atualização anterior à publicação da Resolução n. 01/2012 do CNE e, destes, 15 possuem conteúdos de direitos humanos, mesmo quando ainda não existia a obrigatoriedade normativa. Esses currículos também abordam a temática para além da obrigatoriedade, com ofertas em optativas, atividades complementares, extensão, pesquisa e outras ações acadêmicas curriculares não obrigatórias. Contudo, o estudo não se deteve nesses elementos, pois o objetivo é investigar apenas as opções curriculares que denotam a formação obrigatória para a temática, visto que as demais opções não são possíveis de avaliar por depender da disponibilidade de oferta e das escolhas dos estudantes. Outra observação pertinente é que todos os currículos obtiveram conceito máximo no CPC. Esse resultado pode significar que o INEP somente avalia se os cursos contêm conteúdos sobre a temática, porque no instrumento de avaliação não está explicitada a exigência de inserção de um componente curricular específico sobre o tema. Há que se considerar também que as licenciaturas que não obtiveram nota 5 no CPC podem ter educação em direitos humanos no currículo, mas por não ter atendido quaisquer dos indicadores de avaliação não alcançaram a nota máxima. 
Ademais, observou-se que há maior concentração dos temas referentes à inclusão, diversidade étnico-racial, educação ambiental, direitos políticos e culturais, e entre eles, destaca-se: racismo, preconceito e discriminação dos afrodescendentes e indígenas; diversidades de gênero, incluindo feminismo e direitos da mulher; direito à identidade de gênero, sexual e geracional, assim como sexismo e homofobia, que foram identificados na análise. Entre outros, também relevantes, como inclusão de pessoas com deficiência, com ênfase maior para direitos da pessoa surda. Apesar de os currículos terem uma incidência maior no que tange aos temas relacionados aos direitos individuais, encontrou-se também a presença de conteúdos que implicam tomadas de decisão e participação coletiva nos processos e nos espaços educativos e de convívio social, como os temas gestão democrática, democratização, sustentabilidade e, de forma mais genérica, direitos sociais, tais como: direito à saúde e à educação, assim como direitos políticos, ambientais e culturais, citados anteriormente, que denota a compreensão de que os direitos humanos devem interligar a relação humana com todas as espécies do planeta de forma eticamente sustentável.

É preciso levar em consideração também que a atualização de um projeto pedagógico de curso de graduação é um processo complexo e exige a participação coletiva, democrática e engajada de todos os envolvidos. Portanto, requer tempo para elaboração, apreciação pelas partes, discussão, revisões, debates e deliberação por todas as instâncias administrativas e pedagógicas das IFES, o que pode levar alguns meses ou até mesmo anos para ser finalizado. Entende-se que nos últimos anos as mudanças constantes de governantes, cortes de investimentos para a educação, contingenciamento financeiro e ataques à função social das universidades federais, a destituição dos conselheiros do CNE em meios aos debates que envolviam uma nova base nacional curricular para a educação básica e formação docente e, posteriormente, a aprovação dessas bases, à revelia das entidades e dos profissionais da educação, trazem para o cenário educacional brasileiro conflitos e incertezas quanto aos rumos que o poder estatal tem dado às políticas públicas dedicadas a esse setor. Todavia, considera-se também que as instituições públicas federais podem e devem se posicionar politicamente contra as ações governamentais supracitadas e muitas têm feito isso bravamente. Para tanto, implementar currículos centrados na educação em direitos humanos é parte desse processo de resistência e de luta contra as violações de direitos, principalmente, as geradas por governos autoritários que desconsideram a educação como um direito social constitucional e insistem em usá-la como mercadoria.

Nesta compreensão, considera-se que as IFES vêm construindo currículos mais engajados com as demandas sociais e com a formação de futuros professores direcionada para uma cultura em direitos humanos. Contudo, salienta-se que diante de tantas violações de direitos que ocorrem cotidianamente na sociedade brasileira, inclusive as advindas dos governantes, é preciso que os profissionais envolvidos na construção curricular estejam atentos às demandas da sociedade e da formação de professores. Porque educar em prol dos direitos humanos também é educar pelo reconhecimento e reivindicação do direito à educação de qualidade. A formação docente como fator indissociável da melhoria da qualidade da educação não pode ficar à margem da formação para a educação em direitos humanos.

Segue-se acreditando na importância da ênfase curricular em direitos humanos de modo que não seja ofertada apenas uma disciplina isolada ou conteúdos isolados, mas que 
seja uma formação transversalizada, que direcione todo o currículo, em todo o percurso formativo do licenciando. Consequentemente, entende-se que essa transversalização deve ser efetivada a partir de metodologias que possibilitem a interdisciplinaridade entre os saberes acadêmicos. E, por fım, que as políticas públicas para a formação de professores deixem de ser uma política de governo e passem a ser uma política formativa, construída de forma coletiva e democrática.

No que diz respeito às limitações da pesquisa, há que se considerar que, na abordagem documental dos currículos prescritos, não é possível identificar como se traduzem esses mesmos currículos no cotidiano pedagógico, nem o modo como seus atores conduzirão essa temática no currículo em ação, considerando também que o currículo é construído no cotidiano educativo, na tradução de seus atores dos currículos prescritos, fazendo-se a cada momento nas salas de aula, nas relações entre alunos/as e professores/as e em tantos lugares da vida.

\section{Referências}

AGUIAR, Márcia Ângela da Silva. Relato da resistência à instituição da BNCC pelo conselho nacional de educação mediante pedido de vista e declarações de votos. In: AGUIAR, Márcia Ângela da Silva; DOURAD0, Luiz Fernandes (org.). BNCC na contramão do PNE 2014-2024: avaliação e perspectivas. Recife: Anpae, 2018. p. 8-22.

ALMEIDA FILHO, Naomar de. Transdisciplinaridade e saúde coletiva. Ciência \& Saúde Coletiva, Rio de Janeiro, v. 2, n. 1/2, p. 5-20, 1997.

ANPED. Associação Nacional de Pós-Graduação e Pesquisa em Educação. Uma formação formatada. [S. I.]: Anped, 2019. Disponível em: http://www.anped.org.br/news/posicao-da-anped-sobre-texto-referenciadcn-e-bncc-para-formacao-inicial-e-continuada-de. Acesso em: 27 jan. 2020. p. 1-14.

APPLE, Michael Whitman. A luta pela democracia na educação crítica. Revista e-Curriculum, São Paulo, v.15, n. 4, p. 894- 926, out./dez. 2017.

APPLE, Michael Whitman. Para além da lógica de mercado: compreendendo e opondo-se ao neoliberalismo. Tradução de Gillka Leite Garcia e Luciana Ache. Rio de janeiro: DP \& A, 2005.

ARENDT, Hannah. As origens do totalitarismo. Tradução de Roberto Raposo. São Paulo: Companhia das Letras: 1989.

ARROYO, Miguel González. Pedagogias em movimento: 0 que temos a aprender dos movimentos sociais? Currículo sem Fronteiras, v. 3, n. 1, p. 28-49, jan./jun. 2003.

BALL, Stephen John. Reformar escolas: reformar professores e os terrores da performatividade. Revista Portuguesa de Educação, Braga, v. 15, n. 2, p. 3-23, 2002.

BITTENCOURT, Hélio Radke et al. Mudanças nos pesos do CPC e seu impacto nos resultados de avaliação 
em universidades federais e privadas. Avaliação, Campinas; Sorocaba, v. 15, n. 3, p. 147-166, 2010. BOAVENTURA, Edivaldo Machado. Um ensaio de sistematização do direito educacional. Revista de Informação Legislativa, Brasilia, DF, v. 33, n. 131, p. 31-57, jul./set. 1996.

BRAGA, Isabela Cristina Marins; MACHADO, Juliana Lacerda; GUIMARÃES-IOSIF, Ranilce Mascarenhas. A política educacional no contexto neoliberal e suas implicações na profissionalização docente da educação básica. In: CUNHA, Célio da; JESUS, Wellington Ferreira de; GUIMARÃES-IOSIF, Ralnice (org.). A educação em novas arenas: políticas, pesquisas e perspectivas. Brasília, DF: Liber Livro: Unesco, 2014. p.151-168.

BRASIL. Constituição da República Federativa do Brasil de 1988. Brasília, DF: Presidência da República, 1988. Disponível em: http://www.planalto.gov.br/ccivil_03/constituicao/constituicao.htm. Acesso em: 15 fev. 2020.

BRASIL. Parecer CNE/CP, n. 8/2012, homologado em 30 de maio de 2012. Diretrizes Curriculares Nacionais para Educação em Direitos Humanos. Diário Oficial da União, Brasília, DF, seção I, p. 33, maio $2012 a$. Disponível em: http://portal.mec.gov.br/index.php?option=com_docman\&view=download\&alias=10389pcp008-12-pdf\&category_slug=marco-2012-pdf\&ltemid=30192. Acesso em: 8 nov. 2018.

BRASIL. Resolução n 1, de 30 de maio de 2012. Estabelece as Diretrizes Curriculares Nacionais para Educação em Direitos Humanos. Diário Oficial [da] União, Brasília, DF, seção I, p. 48, maio 2012b. Disponível em: portal.mec.gov.br/docman/maio-2012-pdf/10889-rcp001-12. Acesso em: 11 dez. 2017.

BRASIL. Casa Civil. Subchefia para Assuntos Jurídicos. Lei n. 13.005, de 25 de junho de 2014. Aprova 0 Plano Nacional de Educação. Brasília, DF: Casa Civil, 2014. Disponível em: http://www.planalto.gov.br/ ccivil_03/_ato2011-2014/2014/lei//13005.htm. Acesso em: 15 fev. 2020.

BRASIL. Instituto Nacional de Estudos e Pesquisas Educacionais Anísio Teixeira. Sistema Nacional de Avaliação da Educação Superior. Caracterização dos cursos de graduação: análise do Conceito Preliminar de Curso (CPC) obtidos em 2008. v. 2. Brasília, DF: INEP, 2015.

BRASIL. Ministério da Educação. Formação superior para a docência na educação básica. Brasília, DF: MEC, 2020. Disponível em: http://portal.mec.gov.br/pet/323-secretarias-112877938/orgaos-vinculados82187207/12861-formacao-superior-para-a-docencia-na-educacao-basica. Acesso em: 19 set. 2020.

BRASIL. Ministério da Educação. Instituto Nacional de Estudos e Pesquisas Educacionais Anísio Teixeira. Instrumentos de avaliação de cursos de graduação presencial e a distância: reconhecimento e renovação de reconhecimento. Brasília, DF: MEC, 2017. Disponível em: http://download.inep.gov.br/educacao_superior/ avaliacao_cursos_graduacao/instrumentos/2017/curso_reconhecimento.pdf. Acesso em: 8 nov. 2018.

BRASIL. Ministério da Educação. Instituto Nacional de Estudos e Pesquisas Educacionais Anísio Teixeira. Portaria n. 515, 14 de junho de 2018. Brasília, DF: MEC, 2018. Disponível em: http://download.inep.gov. br/educacao_superior/indicadores/legislacao/2018/portaria_n515_de_14062018_define_indicadores_ qualidade_2017.pdf. Acesso em: 2 nov. 2018.

CAMARGO, Brigido Vizeu; JUSTO, Ana Maria. Iramuteq: um software gratuito para análise de dados textuais. Temas em Psicologia, Ribeirão Preto, v. 21, n. 2, p. 513-518, dez. 2013b. 
CAMARG0, Brigido Vizeu; JUSTO, Ana Maria. Tutorial para uso do software de análise textual Iramuteq. Florianópolis: UFSC, 2013a. Disponível em: http://www.iramuteq.org/documentation/fichiers/tutoriel-enportugais. Acesso em: 2 fev. 2020.

CANDAU, Vera Maria Ferrão. Ênfases e omissões no currículo. Educação \& Sociedade, Campinss, v. 23, n. 78, p. 296-29, abr. 2002.

CANDAU, Vera Maria Ferrão et al. Educação em direitos humanos e formação de professores(as). São Paulo: Cortez, 2013. (Docência em formação: saberes pedagógicos).

CELLARD, André. Análise documental. In: POUPART, Jean et al. A pesquisa qualitativa: enfoques epistemológicos e metodológicos. Tradução de Ana Cristina Nasser. Petrópolis: Vozes, 2008. p. 295-316

DOURAD0, Luiz Fernandes. Diretrizes curriculares nacionais para a formação inicial e continuada dos profissionais do magistério da educação básica: concepções e desafios. Educação \& Sociedade, Campinas, v. 36, n. 131, p. 299-324, 2015.

FREIRE, Paulo. El grito manso. Buenos Aires: Siglo XIX, 2003.

GAD0TTI, Moacir. Educação e poder: introdução à pedagogia do conflito. 13. ed. São Paulo: Cortez, 2003.

GALLO, Sílvio. Transversalidade e educação: pensando uma educação não-disciplinar. In: ALVES, Nilda; GARCIA, Regina Leite (org.). 0 sentido da escola. Rio de Janeiro: DP\&A, 2000. p. 16-40.

GARCIA, Marcos Leite. Direitos humanos do bem viver: entre o conceito de bem viver e 0 novo constitucionalismo latino-americano. Revista de Direito e Sustentabilidade, Florianópolis, v. 1, n. 2, p. 246265, jul./dez. 2015.

GATTI, Bernardete Angelina. Formação de professores no Brasil: características e problemas. Educação \& Sociedade, Campinas, v. 31, n. 113, p. 1355-1379, dez. 2010.

GIROUX, Henry. 0s professores como intelectuais: rumo a uma pedagogia crítica da aprendizagem. Trad. Daniel Bueno. Porto Alegre: Artes Médicas, 1997.

G00DSON, Ivor. A construção social do currículo. Tradução Maria João Carvalho. Lisboa: Educa, 1997.

GOODSON, Ivor. Currículo, narrativa e o futuro social. Revista Brasileira de Educação, Rio de Janeiro, v. 12, n. 35, p. 241-252, 2007.

GUDYNAS, Eduardo; ACOSTA, Alberto. El buen vivir más allá del desarrollo. Revista Quéhacer, Lima, n. 181, p. 70-81, Feb./Mar. 2011.

IMBERNÓN, Francisco. Formação docente e profissional: formar-se para a mudança e incerteza. Trad. Silvana Cobucci Leite. 9. ed. São Paulo: Cortez, 2011. (Questões da nossa época).

JORDELET, Denise. A representação: noção transversal, ferramenta da transdisciplinaridade. Cadernos de Pesquisa, São Paulo, v. 46, n. 162, p. 1258-1271, out./dez. 2016. 
KAMI, Maria Terumi Maruyam et al. Trabalho no consultório na rua: uso do software Iramuteq no apoio à pesquisa qualitativa. Escola Anna Nery, Rio de Janeiro, v. 20, n. 3, p. 1-5, 2016.

LOPES, Alice Casimiro. Discursos nas políticas de currículo. Currículo sem Fronteiras, Rio de Janeiro, v.6, n. 2, p. 33-52, jul./dez. 2006.

LOPES, Alice Casimiro; MACED0, Elizabeth. Contribuições de Stephen Ball para o estudo de políticas de currículo. In: BALL, Stephen John; MAINARDES, Jefferson. Políticas educacionais: questões e dilemas. São Paulo: Cortez, 2011. p. 248-282.

MACED0, Elizabeth. Base Nacional Curricular Comum: novas formas de sociabilidade produzindo sentidos para educação. Revista e-Curriculum, São Paulo, v. 12, n. 03, p.1530-1555, out./dez. 2014.

MACEDO, Roberto Sidnei. Currículo: campo, conceito e pesquisa. 7. ed. Petrópolis: Vozes, 2017.

MOREIRA; Antonio Flavio Barbosa; SILVA, Tomaz Tadeu da (org.). Currículo, cultura e sociedade. Tradução Maria Aparecida Baptista. 7. ed. São Paulo: Cortez, 2002.

MORIN, Edgar. A cabeça bem-feita: repensar a reforma, reformar o pensamento. Tradução Eloá Jacobina. 8. ed. Rio de Janeiro: Bertrand Brasil, 2003.

NOLETO, Marlova Jovchelovitch. Prefácio. In: RANIERI, Nina Beatriz Stocco; ALVES, Ângela Limongi Alvarenga. Direito à educação e direitos na educação em perspectiva interdisciplinar. São Paulo: Cátedra Unesco de Direto à Educação: Universidade de São Paulo, 2018. p.5-6.

NÓVOA, Antonio. Entre a formação e a profissão: ensaio sobre o modo como nos tornamos professores. Currículo sem Fronteiras, Rio de Janeiro, v. 19, n. 1, p. 198-208, jan./abr. 2019.

OLIVEIRA, Bruna Pinotti Garcia; LAZARI, Rafael de. Manual de direitos humanos. 4. ed. Salvador: JusPodvim, 2018.

ONU. Organização das Nações Unidas. Carta internacional dos direitos humanos. [S. I.]: ONU, 1948a. Disponível em: https://nacoesunidas.org/direitoshumanos/declaracao/. Acesso em: 26 nov. 2018.

ONU. Organização das Nações Unidas. Conferência Mundial dos Direitos Humanos, Declaração e Programa de Ação de Viena. [S. I.]: ONU, 1993. Disponível em: http://www.direitoshumanos.usp.br/index.php/ Sistema-Global.-Declara\%C3\%A7\%C3\%B5es-e-Tratados-Internacionais-de-rote\%C3\%A7\%C3\%A30/ declaracao-e-programa-de-acao-de-viena.html. Acesso em: 26 nov. 2018.

ONU. Organização das Nações Unidas. Declaração Universal dos Direitos Humanos de 10 de dezembro de 1948. [S. I.]: ONU, 1948b. Disponível em: https://nacoesunidas.org/wp-content/uploads/2018/10/DUDH. pdf. Acesso em: 26 nov. 2018.

ONU. Organização das Nações Unidas. Diretrizes para planos nacionais de ação para educação em direitos humanos. Resolução A/52/469/Add, 1 D, 20 out. 1997. Disponível em: 1997.http://www.dhnet.org.br/dados/ pp/edh/mundo/onu_diretrizes_planos_nac.pdf. Acesso em: 01 mar. 2020. 
ONU. Organização das Nações Unidas. Resolução n. 49/18. Década das Nações Unidas para a educação em matéria de direitos humanos. 94ª reunião plenária 23 de dezembro de 1994. Disponível em: http://gddc. ministeriopublico.pt/sites/default/files/documentos/pdf/serie_decada_1_b_nacoes_unidas_educacao_ dh_.pdf. Acesso em: 01 mar. 2020.

ONU. Organização das Nações Unidas. Resolución 66/137 aprobada el 19 de diciembre de 2011. Declaración de las Naciones Unidas sobre educación y formación en materia de derechos humanos. [S. I.]: ONU, 2011. Disponível em: https://documents-dds-ny.un.org/doc/UND0C/GEN/N11/467/07/PDF/N1146707. pdf?OpenElement. Acesso em: 26 nov. 2018.

OPERTTI, Renato; KANG, Hyekyung; MAGNI, Giorgia. Comparative analysis of the national curriculum frameworks of five countries: Brazil, Cambodia, Finland, Kenya and Peru. [S. I.]: ONU: Unesco, 2018.

PARASKEVA, João Menelau; GANDIN, Luis Armando; HYPOLITO, Álvaro Moreira. Imperiosa necessidade de uma teoria e prática pedagógica radical crítica: diálogo com Jurjo Torres Santomé. Currículo sem Fronteiras, Rio de Janerio, v. 4, n. 2, p. 5-32, jul./dez. 2004.

RAMOS, André de Carvalho. Curso de direitos humanos. 4. ed. São Paulo: Saraiva, 2017.

RANIERI, Nina Beatriz Stocco. 0 direito educacional no sistema jurídico brasileiro. In: Justiça pela qualidade na educação: Associação Brasileira de Magistrados, Promotores de Justiça e Defensores Públicos da Infância e da Juventude. Todos pela Educação. São Paulo: Saraiva, 2013. p. 55-103.

RICHARDSON, Roberto Jarry. Pesquisa social: métodos e técnicas. 3. ed. São Paulo: Atlas, 2012. Colaboradores José Augusto de Souza Peres et al.

SACRISTÁN, José Gimeno (org.). Saberes e incertezas sobre o currículo. Porto Alegre: Penso, 2013.

SANTOMÉ, Jurjo Torres. As culturas negadas e silenciadas no currículo. In: SILVA, Tomaz Tadeu da. Alienígenas na sala de aula. Petropólis: Vozes, 2013. p. 159-177.

SANTOS, Akiko. Complexidade e transdisciplinaridade em educação: cinco princípios para resgatar o elo perdido. Revista Brasileira de Educação, Rio de Janeiro, v. 13, n. 37, p. 71-83, abr. 2008.

SANTOS, Boaventura de Sousa. A universidade do século XXI: para uma reforma democrática e emancipatória da universidade. 3. ed. São Paulo: Cortez, 2011.

SANTOS, Boaventura de Sousa; MARTINS, Bruno Sena (org.). 0 pluriverso dos direitos humanos: a diversidade das lutas por dignidade. Belo Horizonte: Autêntica, 2019. p. 514 (Epistemologias do sul; 2).

SILVA, Aida Maria Monteiro; TAVARES, Celma. Educação em direitos humanos no Brasil: contexto, processo de desenvolvimento, conquistas e limites. Revista Educação, Porto Alegre, v. 36, n. 1, p. 50-58, jan./abr. 2013.

SILVA, Tomaz Tadeu da. Documentos de identidade: uma introdução às teorias do currículo. 3. ed. Belo Horizonte: Autêntica, 2017. 
SILVEIRA, Rosa Maria Godoy et al. Educação em direitos humanos: fundamentos teórico-metodológicos. João Pessoa: Universitária, 2007.

TAVARES, Celma. Educar em direitos humanos, o desafio da formação dos educadores numa perspectiva interdisciplinar. In: SILVEIRA, Rosa Maria Godoy et al. Educação em direitos humanos: fundamentos teóricometodológicos. João Pessoa: Universitária, 2007. p. 487-503.

TRAVERSINI, Clarice Salete. Currículo e avaliação na contemporaneidade: há lugar para a diferença em tempos imperativos dos números? In: FAVACHO, André Márcio Picanço; PACHECO, José Augusto; SALES, Shirlei Rezende. Currículo, conhecimento e avaliação: divergências e tensões. Curitiba: CRV, 2013. p. 117-190.

UNESCO. Plano de ação do Programa Mundial para Educação em Direitos Humanos: primeira fase. Nova York; Genebra, Unesco, 2006. Disponível em: http://www.dhnet.org.br/dados/textos/edh/br/plano_acao_ programa_mundial_edh_pt.pdf. Acesso em: 25 nov. 2018.

UNESCO. Plano de ação do Programa Mundial para Educação em Direitos Humanos: segunda fase. Brasília, DF: Unesco, 2012. Disponível em: http://unesdoc.unesco.org/images/0021/002173/217350por.pdf. Acesso em: 25 nov. 2018.

UNESCO. Plano de ação do Programa Mundial para Educação em Direitos Humanos: terceira fase. Brasília, DF: Unesco, 2015. Disponível em: http://unesdoc.unesco.org/images/0023/002329/232922P0R.pdf. Acesso em: 25 nov. 2018.

Recebido em: 02.06.2020

Revisado em: 24.11.2020

Aprovado em: 10.12.2021

Daiane da Luz Silva é pedagoga do quadro de técnico-administrativos em educação da Universidade Federal da Bahia (UFBA). Mestrado em estudos interdisciplinares sobre a Universidade (UFBA).

Maria Constantina Caputo é professora associada do bacharelado interdisciplinar em saúde na Universidade Federal da Bahia (UFBA) e membro permanente do Programa de PósGraduação em Estudos Interdisciplinares sobre a Universidade (UFBA). Doutorado em saúde coletiva (UFBA).

Renata Meira Veras é professora associada do bacharelado interdisciplinar em saúde na Universidade Federal da Bahia (UFBA) e membro permanente do Programa de Pós-Graduação em Estudos Interdisciplinares sobre a Universidade (UFBA) e membro permanente do Programa de Pós-Graduação em Psicologia (UFBA). Bolsista Produtividade CNPq, nível 2. Doutorado em psicologia social pela Universidade Federal do Rio Grande do Norte (UFRN). 